\title{
Pap smear as early diagnostic tool for cervical cancer- A life saviour
}

\author{
Ramu S. ${ }^{1}$, Bindu B.J. ${ }^{2}$, Murthy N. ${ }^{3}$ \\ ${ }^{1}$ Dr. Shwetha Ramu, Assistant Professor, ${ }^{2}$ Dr. Bindu B. J, Assistant Professor, ${ }^{3}$ Dr. Narayana Murthy, Professor and Head, \\ all authors are affiliated with Department of Pathology, Basaveshwara Medical College \& Hospital, Chitradurga, \\ Karnataka, India.
}

Corresponding Author: Dr. Bindu. B. J., Assistant Professor, Department of Pathology, Basaveshwara Medical College \& Hospital, SJM Campus, NH-4 Bypass, Chitradurga. Karnataka. E-mail: shwethachandan@gmail.com

\begin{abstract}
Background: Cervical cancer is a leading cause of mortality and morbidity among women globally and most common gynaecological cancer in developing countries. Papanicolaou smear study is a simple and cost effective screening test for cervical cancer. The aim of this study is to evaluate and interpret the pattern of cervical Pap smear cytology in a tertiary hospital. The interpretation and reporting of the Pap smear is based on 2001 Bethesda system. Materials and Methods: This is a retrospective study conducted at Department of Pathology, Basaveshwara Medical College, Hospital and Research Centre, Chitradurga, Karnataka, India. The study was conducted over a period of two years from June 2015 to May 2017. All pap smears received in the department of Pathology during study period were included. Results: A total of 2210 pap smears were reported in the study period. Majority of the cases were inflammatory smears $(35.88 \%)$ and Negative for Intraepithelial lesion or malignancy (49.86\%). Candidiasis, Bacterial vaginosis, Trichomonas vaginalis, atrophy and reactive cellular changes associated with inflammation were seen in $0.49 \%, 0.72 \%, 0.36 \%, 8.91 \%$ and $0.40 \%$ cases respectively. $0.31 \%$ Vault smears were studied. Epithelial cell abnormalities (1.4\%) include Atypical squamous cells of undetermined significance $(0.4 \%)$, Low grade squamous intraepithelial lesion $(0.63 \%)$ and High grade intraepithelial lesion $(0.31 \%) .88 \%$ of Low grade squamous intraepithelial lesion was seen in reproductive age group (18-50 years). Conclusion: Cervical cancer is the most common gynaecological cancer in the developing countries. Pap smear is the simple, easy and cost effective screening tool to detect premalignant and malignant cervical lesions, and reduce the mortality due to cervical cancer by early diagnosis and treatment.
\end{abstract}

Keywords: Bethesda system, Pap smear, Cervical precancerous lesions, LSIL, HSIL, ASCUS, Cervical cancer.

\section{Introduction}

Cervical cancer is the most common gynaecological cancer leading to death in developing countries [1-4]. In 2017, it ranks as $2^{\text {nd }}$ most frequent cancer among women in India next only to breast cancer and the $2^{\text {nd }}$ most frequent cancer among women between 15 and 44 years of age. Every year 122844 women are diagnosed with cervical cancer and 67477 died from the disease [5]. With early diagnosis and treatment, morbidityand mortality may be reduced by $70 \%$ and $80 \%$ respectively [6].

In developing countries, the higher prevalence of cervical cancer is due to ineffective screening programmes. Pap smear is a simple, convenient, cost effective and reliable test for early screening of cervical

Manuscript received: $26^{\text {th }}$ November 2017

Reviewed: $6^{\text {th }}$ December 2017

Author Corrected: $14^{\text {th }}$ December 2017

Accepted for Publication: $19^{\text {th }}$ December 2017 lesions. Since its introduction there has been a dramatic reduction in the incidence and mortality of invasive cervical cancer worldwide [1,7-9]. The Papanicolaou test also known as Pap smear is a screening method used to detect potentially precancerous and cancerous processes in the cervix. Greek doctor Georgios Papanikolaou invented this test and it was named after $\operatorname{him}[6,10]$.

The 2001 Bethesda system terminology reflects important advances in biological understanding of cervical neoplasia and cervical screening technology and is most widely used system for describing Pap smear result [7-9].

This study was done to evaluate the pattern of cervical pap smear cytology and find out the incidence of epithelial cell abnormalities. 


\section{Original Research Article}

\section{Materials and Methods}

Place, type and duration of study: This is a retrospective study done at Department of Pathology, Basaveshwara Medical College, Hospital and Research centre, Chitradurga, Karnataka, India for a period of two years from June 2015 to May 2017.

Sampling methods and sample collection: Prior to the study, permission was obtained from Institutional ethical Committee. All cervical pap smears received in the Department of Pathology during the study period were included. Proforma was filled and data were collected. A total of 2210 pap smears were reported in the study period. After receiving, the slides were fixed in 95\% ethyl alcohol and stained with Papanicolaou stain by cyto technicians. Slides were then mounted with DPX (Distrene Dibutyl phthalate Xylene) and examined by pathologists. The result of these pap smears was based on 2001 Bethesda System for Reporting Cervical Cytologic Diagnoses (Box 1). All the data were manually collected and subsequently analysed.

Inclusion criteria: Women aged between 18 to 80 years.

Exclusion criteria: Women aged less than 18 years and more than 80 years.

\section{Results}

A total of 2210 pap smears were analysed during the study period. The age of the patients in the present study were ranged from 18 to 80 years (Table 1). Majority (89\%) of the pap smears were from the reproductive age group (18- 50 years). $0.63 \%$ of pap smears were from the patients aged below 18 years and $0.99 \%$ from the patients aged above 70 years. Cervical Pap smear findings were tabulated in Table 2.

Table-1: Age wise distribution of total number of patients

\begin{tabular}{|c|c|c|}
\hline $\begin{array}{c}\text { Age group } \\
\text { (In years) }\end{array}$ & Number of patients & Percentage (\%) \\
\hline$<18$ & 14 & 0.63 \\
\hline $18-50$ & 1967 & 89 \\
\hline $50-60$ & 168 & 7.6 \\
\hline $60-70$ & 39 & 1.78 \\
\hline$>70$ & 22 & 0.99 \\
\hline
\end{tabular}

Table-2: Pap smear findings according to 2001 Bethesda system

\begin{tabular}{|c|c|c|}
\hline Interpretation/Result & Number of cases & Percentage (\%) \\
\hline Negative for intraepithelial lesion or malignancy & 793 & 36 \\
\hline Atrophic smear & 197 & 2.01 \\
\hline Unsatisfactory for evaluation & 45 & 49.86 \\
\hline Inflammatory smear & 1102 & 0.45 \\
\hline Candidiasis & 11 & 0.72 \\
\hline Shift in vaginal flora suggesting bacterial vaginosis & 16 & 0.36 \\
\hline Trichomonas vaginalis & 08 & 0.63 \\
\hline Low grade intraepithelial lesion(LSIL) & 14 & 0.31 \\
\hline High grade intraepithelial lesion(HSIL) & 07 & 0.4 \\
\hline Atypical squamous cells of undetermined significance & 09 & 0.04 \\
\hline (ASCUS) & 01 & 0.31 \\
\hline Vault smear & 07 & $\mathbf{1 0 0}$ \\
\hline
\end{tabular}

There were $2.01 \%$ cases of unsatisfactory smear. The most common cause for unsatisfactory smear was obscuring inflammation $(55.3 \%)$ where more than $75 \%$ of squamous epithelial cells were obscured. $34.2 \%$ cases showed absence of endocervical/ transformation zone component, 10.5\% showed obscuring blood and low squamous cellularity.49.86\% cases were Inflammatory smears and $35.88 \%$ were Negative for Intraepithelial Lesion or Malignancy. 


\section{Original Research Article}

Epithelial cell abnormalities were seen in $1.40 \%$ cases which includes LSIL $(0.63 \%)$, HSIL $(0.31 \%)$, ASCUS $(0.40 \%)$ and atypical glandular cells $(0.04 \%)$. LSIL was most commonly seen in reproductive age group (15-50 years) and HSIL was most commonly seen in peri menopausal age group (51-65 years). Atrophic and reactive cellular changes were seen in $8.91 \%$ and $0.04 \% \%$ respectively. Organisms associated lesions like candidiasis $(0.45 \%)$, bacterial vaginosis $(0.72 \%)$ and trichomonas vaginalis $(0.36 \%)$ were also seen in our study.

\section{Discussion}

Cervical carcinoma alone is responsible for about $5 \%$ of all cancer deaths in womenworldwide [1, 14]. It has been reported that in developing countries more than 200,000-300,000 women die from cervical cancer each year. Initiation of national screening program in the developed countries has resulted in a marked decrease in the cervical cancer related deaths $[1,15]$. Not only in developing countries, tremendous amount of effort is devoted to cervical cancer screening in United States $[1,16]$. The incidence of cervical cancer has decreased more than $50 \%$ in the past thirty years because of widespread screening with cervical cytology $[1,8]$. Considering the efficacy of pap smear cytology in preventing cervical cancer it is advocated that it should be initiated in all women at the age of 21 years[1,12].

In our study of cervical Pap smear cytology, age of the patients ranged from 18 to 80 years were included and the predominant population in the present study were between $18-50$ years $(89 \%)$. This finding was similar to the studies done by Pudasaini et al, Hirachand et al, Ranabhat et al, Bukhar et al and Bamanikar et al [1,79,17].

The present study shows $0.63 \%$ of pap smears were from the patients aged below 18 years than other age groups. This similar result $(0.6 \%)$ was seen in the study done by pudasaini et al in Nepal on cervical pap smear in a tertiary hospital.However, in the studies done in mid western part of Nepal and Bangladesh, there were no cases below 20 years $[8,12]$. Contrast to this study and our study, the number of cases of pap smear aged below 20 years was quite high (11.7\%) in Pakistanwhich was depicted in the study done by Haider et al [18].

There were $2.01 \%$ cases of unsatisfactory smear in the present study and the most common cause for unsatisfactorysmear was obscuring dense inflammation and blood, absence of endocervical or transformation zone component and low squamous cellularity. This is similar to the study done in Pakistan $(1.8 \%)$ by Bukhari et al [9]. Lots of variation regarding unsatisfactory smear was seen in several studies conducted in different places. Study done in Kathmandu revealed $0.3 \%$ of unsatisfactory smear, which is lower than in our study
[7]. In contrast to our study, the incidence of unsatisfactory smear was quite high in the studies conducted by Patel et al, Khan et al, Bamanikar et al and Vaghela et alrespectively $(11.9 \%, 9.5 \%, 5.7 \%$ and $4.8 \%)[13,15,17,19]$. In the present study, Negative for Intraepithelial Lesion or Malignancy was seen in $35.88 \%$ cases. Whereas the studies done by Vaghela et al and Saha et al, Negative for Intraepithelial Lesion or Malignancy were $47 \%$ and $50.6 \%$ respectively, which is higher than in our study $[19,20]$.

Epithelial cell abnormalities represents $1.40 \%$ cases in our study which includes low grade squamous intraepithelial lesion (LSIL), high grade squamous intraepithelial lesion (HSIL), atypical squamous cells of undetermined significance (ASCUS) and Atypical glandular cells (AGC). Other studies had shown that the prevalence of epithelial cell abnormalities were different in different studies done by Ranabhat et al, Saha et al, Renuka, et al, Nair et al, Tailor et al, Selhi et al, Rizvi et al and Verma et al respectively $(1.7 \%$, $10.3 \%, 1.8 \%, 5.6 \%, 1.8 \%, 2.0 \%, 1.2 \%$ and $13.6 \%$ ) [8,20-26].

Low grade squamous intraepithelial lesion (LSIL) in our study was $0.63 \%$, which is comparable to the other studies conducted by pudasaini et al, Hirachand et al and yeasmin et al respectively $(0.2 \%, 0.15 \%$ and $0.3 \%)[1,7,12]$. High grade squamous intraepithelial lesion (HSIL) was seen in $0.3 \%$ cases in our study that correlates well with the other Studies done in Nepal and India $(0.29 \%, 0.7 \%$ and $0.3 \%) \quad[7,8,12]$. Cases of ASCUS $(0.4 \%)$ was also quite comparable to other studies done by Hirachand et al, Ranabhat et al and Yeasmin et al respectively $(0.51 \%, 0.23 \%$ and $0.2 \%)$ $[7,8,12]$. However in one study done in Gujarat, the incidence of ASCUS (40.74\%) was quite high [23].

LSIL and HSIL were most commonly seen in reproductive age group (18-50 years) and perimenopausal (46-55 years) age group respectively which correlates well with the studies done by Pudasainiet al and Hirachand et al[1,7]. Other studiesconducted by Yeasmin et al and Tailor et al revealed that epithelial cell abnormalities were seen in an age group 40 years and above [12,23]. 
Original Research Article

Atrophic changes were seen in $8.91 \%$ cases in the present study whereas the studies done in Bangladesh and Pakistan shows atrophic changes in 3.0\% and 3.1\% respectively $[12,15]$. Bacterial vaginosis $(0.72 \%)$ was common among the organism associated lesion in our study. Other studies by Vaghela et al, Saha et al, Renuka et al and Verma et al, revealed $1.6 \%, 7.1 \%, 5.4 \%$ and $8.8 \%$ cases of bacterial vaginosis respectively $[19,20,21,26]$.

Trichomonas vaginalis was seen in $0.36 \%$ cases which is in contrast to other studies, where there were $3.2 \%$, $0.7 \%$ and $0.6 \%$ cases [20,23,24]. Pap smear examination should begin as soon as the female are sexually active irrespective of their age and should be practiced as a routine gynaecological screening program. Implementation of pap smear screening program in all parts of developing countries is necessary for early detection of cervical premalignant lesions, which helps in early diagnosis, prompt treatment and reduction in mortality related to cervical cancer.

\section{Conclusion}

Pap smear is a widely accepted and highly effective screening tool for early detection of premalignant and malignant lesions of the cervix,thus helping in prompt treatment at an early stage. Till date Pap smear for cervical cancer is the most useful screening procedure known to reduce the mortality and morbidity associated with cervical malignancy, and thus pap smear a life saviour.

The 2001 Bethesda system used for cervical cytology is a standard method and gives descriptive diagnosis that helps the gynaecologists in an individual patient management. Awareness and education regarding anavailability, utility and importance of Pap smear should be created among all women worldwide.

Funding: Nil, Conflict of interest: None initiated, Permission from IRB: Yes

\section{References}

1. Pudasaini S, Prasad KBR, Rauniyar SK, Pathak R, Pande K, Koirala S, Kafle S. Cervical pap smear- A prospective study in a tertiary hospital. Journal of pathology of Nepal 2015;5:820-23.

2. Tamrakar SR, Chawla CD. A clinical audit of pap smear test for screening of cervical cancer. Nepal Journal of Obstetrics and Gynaecology 2012 Jul-Dec; 7 (14): 21-24.
3. Pradhan B, Pradhan SB, Mital VP. Correlation of pap smear findings with clinical findings and cervical biopsy.KathmanduUnivMedJ2007Oct-Dec;5(4):461-67.

4. Mandakini M Patel, Amrish N Pandya, Jigna Modi. Cervical Pap Smear Study And utility In Cancer Screening, to specify the strategy for Cervical cancer control. National Journal of Community Medicine 2011; 2 (1):49-51.

5. Human Papillomavirus and Related Cancers, India Fact Sheet 2017.

6. Vijaya Lakshmi P, SreeGouri S.R. Study and Analysis of Two Hundred Cervical PAP Smears in Our Hospital. International Journal of Contemporary Medical Research. 2016;3(9):2787-89.

7. Hirachand S, Bajracharya J, Pradhanang S, Lama S. Detection of abnormal cervical cytology in papanicolaou smears in a tertiary care center. J Nepal Med Assoc 2013 Jul-Sep;52(191):462-65.

8. Ranabhat SK, Shrestha R, Tiwari M. Analysis of abnormal epithelial lesions in cervical pap smears in Mid-Western Nepal. Journal of Pathology of Nepal 2011; 1:30-33.

9. Bukhari MH, Saba K, Qamar S, Majeed MM, Niazi S, Naeem S. Clinico-pathological importance of papanicolaou smears for the diagnosis of premalignant and malignant lesions of the cervix. J Cytol 2012 Feb 27; 29 (1): 20-25.

10. Pap smear. By Healthline medical review team. www. healthline.com /health/ pap-smear\# Overview1/ $2015 / 11$.

11. Solomon D, Davey D, Kurman R, Moriarty A, O'Connor D, Prey M, Raab S, Sherman M, Wilbur D, Wright T Jr,Young N. The 2001 Bethesda system: Terminology for reporting results of cervical cytology. JAMA 2002 Apr 24;287(16):2114-19.

12. Yeasmin S, Begum T, Begum LN, Ahmed ASMM, Osman B. Pap smear study and its utility in cervical cancer screening in a tertiary care hospital in Chittagong, Bangladesh. ChattagramMaa-O- Shishu Hospital Medical College Journal 2014 Jan;13(1): 17-19.

13. Patel MM, Pandya AN, Modi J. Cervical pap smear study and its utility in cancer screening to specify the 


\section{Original Research Article}

strategy for cervical cancer control. Natl J Community Med 2011; 2(1):49-51.

14. Mansoor I. Profile of cervical smears cytology in western region of Saudi Arabia. The internet journal of Gynaecology and Obstetrics 2001;1:1-5.

15. Khan MS, Raja FY, Ishfaq G et al. Pap smear screening for pre cancerous conditions of the cervical cancer. Pak J Med Res 2005;44:111-13.

16. Sirovich B, Welch HG. The frequency of pap smear screening in the United States. J Gen Intern Med 2004 Mar;19(3):243-50.

17. Bamanikar SA, Baravkar DS, Chandanwale SS, Dapkekar P. Study of cervical pap smears in a tertiary hospital. Indian medical Gazette 2014 July; 148(7). 250-54.

18. Haider G, Parveen Z, Anjum F, Munir A. Pap smear, an important screening tool to detect precancerous stage of carcinoma of cervix. J Ayub Med Coll Abbottabad 2013 Jan-June;25(1-2):26-27.

19. Vaghela BK, Vaghela VK, Santwani PM. Analysis of abnormal cervical cytology in papanicolaou smears at tertiary care center- a retrospective study. IJBAR 2014;5(1):47-49.
20. Saha K, Sengupta M, Mistry CJ. Cytological findings of conventional cervical papanicolaou smear in a tertiary care hospital. Global Research Analysis 20113; 2:149-51.

21. Renuka N, Sultana A. Cytopathological study of cervical smear: a hospital based retrospective study. Medical journal of Islamic World Academy of Sciences $2014 ; 22(1): 42-49$.

22. Nair RV, Shwetha BR, Manju A, Solanke PV. Papanicolaou (Pap) test screening in a tertiary care teaching hospital in South India. IJMSCI 2015; 2(8): 1260-65.

23. Tailor HJ. Patel RD, Patel PR, Bhagta VM. Study of cervical pap smears in atertiary care hospital of South Gujarat, India. Int J Res Med Sci 2016;4(1):286-88.

24. Selhi PK, Singh A, Kaur H, Sood N. Trends in cervical cytology of conventional pap smears according to revised Bethseda system: a study of 638 cases. IJRRMS 2014 Jan-March;4(1):16-20.

25. Rizvi JH. Rasul S, Ghazali B, Jamal A. Screening for cervical cancer by pap smear. JPMA 1988 Sept; 38:229-31.

26. Verma I, Jain V, Kaur T. Application of Bethesda system for cervical cytology in unhealthy cervix. J ClinDiagn Res 2014 Sep;8(9):26-30.

\section{How to cite this article?}

Ramu S, Bindu B.J, Murthy N. Pap smear as early diagnostic tool for cervical cancer- A life saviour. Trop J Path Micro 2018;4(1):22-26.doi: 10.17511/jopm.2018.i1.04. 